\title{
Article
}

\section{Culturally Relevant Inquiry-Based Laboratory Module Implementations in Upper-Division Genetics and Cell Biology Teaching Laboratories}

\author{
Dimuth Siritunga, María Montero-Rojas, Katherine Carrero, Gladys Toro, \\ Ana Vélez, and Franklin A. Carrero-Martínez
}

Department of Biology, University of Puerto Rico, Mayagüez, PR 00680

Submitted April 11, 2011; Revised June 28, 2011; Accepted June 28, 2011

Monitoring Editor: Robert L. DeHaan

\begin{abstract}
Today, more minority students are entering undergraduate programs than ever before, but they earn only $6 \%$ of all science or engineering PhDs awarded in the United States. Many studies suggest that hands-on research activities enhance students' interest in pursuing a research career. In this paper, we present a model for the implementation of laboratory research in the undergraduate teaching laboratory using a culturally relevant approach to engage students. Laboratory modules were implemented in upper-division genetics and cell biology courses using cassava as the central theme. Students were asked to bring cassava samples from their respective towns, which allowed them to compare their field-collected samples against known lineages from agricultural stations at the end of the implementation. Assessment of content and learning perceptions revealed that our novel approach allowed students to learn while engaged in characterizing Puerto Rican cassava. In two semesters, based on the percentage of students who answered correctly in the premodule assessment for content knowledge, there was an overall improvement of $66 \%$ and $55 \%$ at the end in the genetics course and $24 \%$ and $15 \%$ in the cell biology course. Our proposed pedagogical model enhances students' professional competitiveness by providing students with valuable research skills as they work on a problem to which they can relate.
\end{abstract}

\section{INTRODUCTION}

Allowing undergraduate students to feel the excitement and self-investment that is related to the discovery of new knowledge is now thought to be a better way to educate students in science (National Research Council, 2000, 2003; Lord et al., 2007; Prince and Felder, 2007; Shaffer et al., 2010). Laboratory modules that foster research-oriented or inquirybased exercises are replacing or supplementing the traditional "cookbook"-style lab modules in many disciplines.

DOI: $10.1187 /$ cbe.11-04-0035

Address correspondence to: Dimuth Siritunga (dimuth.siritunga@ upr.edu).

(c) 2011 D. Siritunga et al. CBE—Life Sciences Education (c) 2011 The American Society for Cell Biology. This article is distributed by The American Society for Cell Biology under license from the author(s). It is available to the public under an AttributionNoncommercial-Share Alike 3.0 Unported Creative Commons License (http:/ / creativecommons.org/licenses/by-nc-sa/3.0).

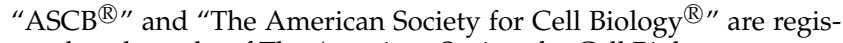
tered trademarks of The American Society for Cell Biology.
Multi-week research or inquiry-based laboratory exercises have been shown to enhance critical thinking, retention of knowledge, technical skills gained, and ability to interpret data, as well as to increase students' interest in science and improve their preparation for postgraduate education (Hathaway et al., 2002; Seymour et al., 2004; Hunter et al., 2007; Russell et al., 2007). One key obstacle when implementing true research-oriented laboratory modules is the availability of tested procedures/techniques; this becomes particularly problematic when the lab exercises are designed for students in very large classes.

In this paper, we describe the development of laboratory modules for a general genetics course ( $\sim 600$ students per year) and a cell biology course ( $\sim 200$ students per year), which, respectively, primarily enroll junior- and senior-level students. The main goal of our modules was to incorporate culturally relevant content and high-quality, researchoriented instruction in undergraduate courses, while increasing the students' ability to understand and use modern molecular biology tools. Because cassava (Manihot esculenta) is an integral part of the diet of Puerto Ricans (18.4 million 
metric tons were consumed in 2007 in the form of mofongo, pasteles, fritas, chips, or boiled cassava), we decided to implement modules based on the study of cassava diversity in Puerto Rico.

Module implementation strategies varied in order to enhance both students' understanding of the science behind the module and hands-on experience. Implementation in the genetics course was spread throughout the semester within four sessions, while the cell biology module was completed in two sessions. This strategy was based mostly on the fact that students generally take the genetics course before the cell biology course.

Our goal for the modules was to allow the untrained undergraduate students to experience the excitement and challenges of original research, while enhancing their understanding of the multidisciplinary nature of modern experimentation. Within this primary goal, we also were attempting to increase the students' ability to learn about and use modern tools of molecular and cellular biology. Students in both courses were asked to bring cassava samples from their hometowns. These samples were assigned unique identifiers and analyzed in the genetics course. To assess genetic diversity of samples brought from the field, students in the genetics course used molecular markers, while students in the cell biology course assessed starch content and visualized other cellular structures using light microscopy. Our specific objectives were divided into research and educational objectives:

\section{Education Objectives}

- Equip biology students with experience in handling modern molecular and cellular techniques and equipment within the scope of an original research project

- Promote students' ability to search for solutions to common scientific problems within a team research effort

- Incorporate and institutionalize modern laboratory exercises into the current course schedule

- Update the laboratory manuals in the genetics and cell biology courses

- Develop skills, such as critical thinking, awareness of contemporary issues, and problem solving, in students

\section{Research Objectives}

- Relate the unknown cassava accessions in Puerto Rico to the varieties of the germplasm collection

- Identify cassava varieties not in the germplasm collection

- Identify and clarify duplicate nomenclature

- Identify the type of starch-amylose and amylopectin-of known cassava varieties

- Identify the type and number of cells in known cassava varieties

\section{Research Project Background}

Knowledge of germplasm diversity and its genetic characterization is an invaluable asset in crop improvement strategies, as well as in conservation strategies. Though cassava has been an important crop and present in the Caribbean since the fifteenth century, the origin of today's cassava in the Caribbean is poorly understood. Evaluation of the Puerto Rican cas- sava population for its diversity and genetic characterization is an invaluable asset in the improvement strategies of cassava. Due to the continuation of traditional farming practices in Puerto Rico, evaluation of its cassava population can potentially lead to the discovery of new varieties. Since maintenance of cassava varieties is conducted in the field by farmers, correct assessment of genetic diversity of those farmer-held varieties can be invaluable for the crop's conservation and the identification of new combinations with maximum genetic variability. These new varieties can then be used for further selection and introgression of desirable genes from diverse germplasm into the available genetic base (Smith, 1984; Cox et al., 1986; Mohammadi and Prasanna, 2003).

A number of molecular methods, such as restriction fragment length polymorphism, random amplification of polymorphic DNA, amplified fragment length polymorphism, single nucleotide polymorphism, and single sequence repeat (SSR) markers (also known as single tandem repeat or microsatellites) have been used to study cassava diversity (Fregene et al., 2003; Kizito et al., 2005). Overall, SSR molecular markers have been the method of choice, since they can be easily adapted for classification and identification of cassava, and are particularly useful for studying the variation in allelic frequency of unlinked loci, which is the preferred way of assessing genetic differentiation. They also exhibit high levels of polymorphisms, are somatically stable, are inherited in a codominant Mendelian manner, and are conducive to automation (Morgante and Olivieri, 1993; Fregene et al., 2003). Fregene et al. (2003) developed a set of SSR markers that are useful for diversity analysis in cassava. Using 33 of these SSR markers, we attempted to assess the diversity of cassava in Puerto Rico. To accomplish this research goal we obtained cassava leaf samples from different townships in Puerto Rico with the help of the $\sim 600$ genetics students. Undergraduate students brought in a sufficient number of samples $(n=162)$ to permit a thorough assessment of diversity of cassava in Puerto Rico. The same samples were also used in the laboratory module for the genetics course, as described below in DNA Extraction, by undergraduate students enrolled in all teaching laboratory sections. This generated a strong sense of student ownership of the work and responsibility for the data, and also led to more enthusiasm for the laboratory exercises. Furthermore, the student analysis of these samples resulted in a recent publication (Montero-Rojas et al., 2011) and a graduate thesis project.

\section{Course and Lab Module Context}

The first part of the implementation took place in the genetics course, which normally includes $\sim 30 \%$ sophomores, $40 \%$ juniors, and 30\% seniors. The students who enroll in this course are not only from the Department of Biology but also from other departments, such as Agronomy and Soils, Horticulture, Food Technology, and Engineering. The course format was $2 \mathrm{~h}$ of lecture and $3 \mathrm{~h}$ of laboratory per week for $15 \mathrm{wk}$. The lecture component of the genetics course was taught by one of four professors, and the number of students per classroom varied between 30 and 60 students. The laboratory component consisted of sections of 18-24 students, and was taught by graduate teaching assistants (TAs) of diverse backgrounds. Because the lecture section of the course covers a broad range of topics, ranging from classical Mendelian 
genetics to molecular genetics, the lab exercises proceeded independently of the lecture section of the course.

The multi-week genetics laboratory module began on week 1 and ended on week 15 . The new lab exercises replaced more "cook-book"-style, stand-alone exercises. Comparatively, the new lab exercises mimicked an actual research project. To achieve the final goal, the students had to work continuously on the same project over the course of several weeks. Throughout the genetics module, the students worked in groups of four, and the students were introduced to the cassava module in week 1 .

The second part of the implementation took part in the cell biology course (1\% sophomores, $21 \%$ juniors, $78 \%$ seniors). Traditionally, most students $(\sim 80 \%)$ follow the suggested curricular sequence, where the genetics course is taken the semester before cell biology. Thus, the majority of students were already familiar with the project, as they were likely to have completed the genetic characterization of cassava. The purpose of the cell biology component was to allow students to gather quantitative and qualitative data from cassava samples. Prior to this module implementation, no plant cellular structures were studied as part of the cell biology laboratory, even though they are covered in the lecture component of the course.

Both modules were initially test-piloted in one laboratory section ( 22 students), and compared with a control laboratory section $(\sim 22$ students) taught by the same TA. The rationale behind this was to minimize any TA-related impact. Furthermore, the TA chosen for the pilot implementation had prior experience teaching the traditional genetics or cell biology laboratory.

\section{METHODS}

\section{Genetics Module}

Sample Collection. The key objective when collecting cassava leaf samples from different townships in Puerto Rico was to make sure that the samples were itemized coherently. With $\sim 600$ students per year enrolling in the genetics course, a clear and resourceful "sample collection form" was prepared (see Supplemental Material). This "sample collection form" was part of a handout developed for this module and was handed to each student during the first week of laboratories. The main objective here was to be able to backtrack any particular sample to the farm from which it originated. Thus, key facts, such as the location of and contact information of the owner of the cassava plant was collected. Furthermore, to ease the archiving of all the samples in the principal investigator's (PI's) research laboratory, an internal coding system was utilized. For example, Fa10-066-1 would represent sample 1 of the lab section 066 during the Fall 2010 semester. Each undergraduate student was asked to collect cassava leaf samples from his or her township; the samples were placed in ziplock plastic bags, which were stored at $4{ }^{\circ} \mathrm{C}$ until their transportation to the genetics laboratory.

DNA Extraction. During the semester prior to the pilot implementation of the lab module, the DNA extraction protocol described by Dellaporta et al. (1983) was modified to fit $1 \mathrm{~h}$ of lab time (see Supplemental Material). An undergraduate research student and a senior graduate student in the PI's research laboratory were assigned the task of modifying the protocol. Once optimized to fit a 1-h time duration, the modified protocol was subsequently tested in the research laboratory by two untrained undergraduate students enrolled in the genetics course during that particular semester under the supervision of the trained undergraduate research student.

During the pilot and full implementation of this lab module, each group of four students extracted DNA from a sample brought by one of its members. With a lab section having four to five groups, DNA from at least four cassava samples was extracted per section. Any unused leaf material was returned back to the marked ziplock bag, and subsequently analyzed in the research laboratory as part of the master's degree thesis of a graduate student, who subjected the samples to a more thorough evaluation using 33 SSR markers (see Assessment of Cassava Diversity in Puerto Rico).

SSR Marker Amplification. Due to the vast number of students enrolled in the genetics course per semester, it was impossible to facilitate each student preparing a polymerase chain reaction (PCR) by adding each component individually. Therefore, the lab coordinator prepared three master mixes prior to the laboratory exercise, and each student added $8 \mu \mathrm{l}$ of Mix1 $\left(\mathrm{MgCl}_{2} / \mathrm{dNTPs} / \mathrm{H}_{2} \mathrm{O}\right), 5 \mu \mathrm{l}$ of Mix2 (Reaction buffer/Taq polymerase/ $\mathrm{H}_{2} \mathrm{O}$ ), $5 \mu$ l of Mix3 (M13 primers/SSR primers/TE buffer), and $7 \mu$ l of cassava DNA to obtain a final PCR containing $10 \mathrm{mM}$ Tris- $\mathrm{HCl}(\mathrm{pH} \mathrm{8.3),}$ $1 \mathrm{U}$ of Taq polymerase, $2 \mathrm{mM} \mathrm{MgCl}, 0.2 \mathrm{mM}$ dNTP mix, 0.5 pmoles of the M13 primer, and 100 pmoles of the SSR primers.

Each group was given DNA samples from the other groups of the lab section to amplify with a single SSR marker. Thus, a particular group would set up four to five PCRs with a single SSR marker. Once all the groups had set up their respective PCRs, the following amplification cycle was utilized: $95^{\circ} \mathrm{C}$ for $5 \mathrm{~min}$, followed by 34 cycles of $94^{\circ} \mathrm{C}$ for $30 \mathrm{~s}, 55^{\circ} \mathrm{C}$ for $45 \mathrm{~s}$, and $72^{\circ} \mathrm{C}$ for $1 \mathrm{~min}$, with a final extension of $5 \mathrm{~min}$ at $72^{\circ} \mathrm{C}$.

Gel Electrophoresis. Though the scoring of SSR markers cannot be performed on normal agarose gel electrophoresis, size difference of some alleles can be visualized if the difference is more than 10-15 base pairs. In addition, the difference between a homozygote sample and heterozygote sample at a particular SSR locus can be observed on an agarose gel. For these reasons, as well as to allow the students the opportunity to gain experience utilizing DNA gel electrophoresis, each group made a standard 1.5\% agarose gel, and ran their PCR samples along with a molecular marker sample.

SSR Marker Evaluation. The addition of the M13 tail sequence to the $5^{\prime}$ end of each forward SSR primer allows the amplicons to be visualized by the fluorescence emitted by the "fluorophore" bound to the M13 primer (third primer added to the PCR). For better resolution, the amplicons were visualized on $6.5 \%$ denaturing polyacrylamide gels on a LICOR 4300 automated DNA sequencer. The molecular weight of each band was assessed by running a 50-350 base pair molecular-size ladder (LI-COR Biosciences, Lincoln, NE) in each gel. Though the lab technician performed this step, the logistics of the technique were shared with the undergraduate students as part of the lab module. The results of the 
SSR marker evaluation on the denaturing polyacrylamide gels were shared with the undergraduate students in a subsequent lab session.

\section{Cell Biology Module}

Light Microscopy. Students were also asked to view root cuttings, which helped in visualization of the cellular and physiological significance of cell-specific nutrient storage. Students cut thin sections of selected root portions and stained them with potassium iodine, followed by several washes to remove excess stain. Samples were then mounted for light microscopy visualization. Students also viewed leaf structures under the microscope. The modified procedure asked the student to cut $5 \mathrm{~mm} \times 5 \mathrm{~mm}$ pieces of leaf, which were then fixed in paraformaldehyde:glutaraldehyde solution. Following incubation and washes in phosphate-buffered saline (PBS), the leaf cuttings were mounted and observed. These results were made available to the PI's research laboratory, which determined whether the samples varied from the unknown cassava samples.

Starch Assessment. On the basis of a modified protocol (Cabral and Carvalho, 2001), students cut $0.5 \mathrm{~g}$ of cassava and macerated it into a paste that was then resuspended in $80 \%$ ethanol and centrifuged. Lugol's solution was added to the sample, and a dilution series was performed. Absorbance was measured at $480 \mathrm{~nm}$ using a Genesis $10 \mathrm{UV}$ Scanning spectrophotometer (Thermo Electron Corporation, Waltham, MA; Hovenkamp-Hermelink et al., 1988). Students were then asked to use the Beer-Lambert's equation to determine the starch concentration present in their cassava samples compared with known controls. As in the genetics module, a student handout was developed for the cell biology module.

\section{Assessment Tools}

Assessment tools focused on evaluating two important aspects: gain of content knowledge and impact on reported self-confidence. The gain-of-content knowledge assessment tool consisted of questions both broad and specific in nature. For example, "What is the use of RNAse in nucleotide extraction?" was used to assess specific knowledge gained, while "Why is cassava an important crop in this world?" was used to assess broad knowledge gained. To minimize students' tendency to guess, all questions in both pre- and postmodule tests had "I don't know" as an option. In addition, the postmodule assessment also contained open-ended questions. These questions allow for the opportunity to provide relevant comments regarding their experiences with the modules. As part of the assessment cycle, these suggestions were evaluated and incorporated wherever appropriate.

During the first two semesters of implementation, the TAs and the lab coordinator/technician were also assessed, using a similar assessment tool (unpublished data). More importantly, the postmodule assessment also contained questions that gave the TAs, lab coordinator, and lab technician a chance to comment on the content and implementation of the new lab exercise. The faculty member in charge of the genetics and cell biology courses met with laboratory coordinators, technicians, and TAs before, during, and after each implementation. This allowed for timely intervention, leading to success- ful implementation of the modules. These interactions with the others involved in the implementation of the modules enhanced our capacity to improve the next implementation cycle.

\section{RESULTS AND DISCUSSION}

\section{Sample Collection}

During the course of implementations (one pilot and two full implementations) we received 162 cassava leaf samples collected by students enrolled in the genetics course at the University of Puerto Rico Mayagüez campus. We developed a sample collection form as part of the modules; this form was made available to the students at the beginning of each semester. From these forms, we determined that collected samples came from 59\% of Puerto Rican municipalities, with higher representation from areas where most of the agricultural land is located. Specifically, a higher number of samples (67) came from the northwestern region, which has the most arable, well-drained soil suitable for cassava growth. Additionally, the majority of the samples (95\%) were collected from home gardens or subsistence farmers. This is to be expected, due to the lack of significant local commercial cassava production and the fact that $\sim 90 \%$ of the cassava consumed in Puerto Rico is imported (Goenaga et al., 2002). The strategy of engaging students in large-scale sample collection allowed us to properly analyze the diversity present in Puerto Rican cassava (see Assessment of Cassava Diversity in Puerto Rico).

\section{DNA Extraction, SSR Marker Amplification, and Gel Electrophoresis}

Each group of students performed their own DNA extraction, set up PCRs with one of the SSR markers (their own plus other groups' DNA samples), and analyzed the banding pattern on agarose gel electrophoresis. Figure 1A shows the quality of the DNA extracted from cassava leaves by the students of a single lab section (five groups). After completion of the DNA extraction, $2 \mu$ of the sample was separated by gel electrophoresis for visualization of genomic DNA. During the three semesters, almost all sections were able to extract DNA from cassava leaves using the modified Dellaporta et al. (1983) method described previously. Approximately 75\% of the time, the fluorescent PCRs set up by individual students succeeded. With each group setting up four to five PCRs, every student had the opportunity to set up the PCR for at least one sample. Figure 1B shows gel electrophoresis of such PCR amplicons, including the molecular marker ladder. The gels were made and run completely by the undergraduate students. On completion of the gels, the students were asked to assess the gels and state the likely sizes of the bands, the homozygous versus heterozygous nature of the samples, and the allelic differences that existed between samples.

In this technique, the allelic differences or similarities between DNA samples are best visualized through the fluorescence emitted by the M13 primer; this was accomplished by the separation of the amplicons on $6.5 \%$ denaturing polyacrylamide gels on a LI-COR 4300 automated DNA sequencer (LI-COR Biosciences). This step was performed by the lab technician, due to the cost of the machine and the 


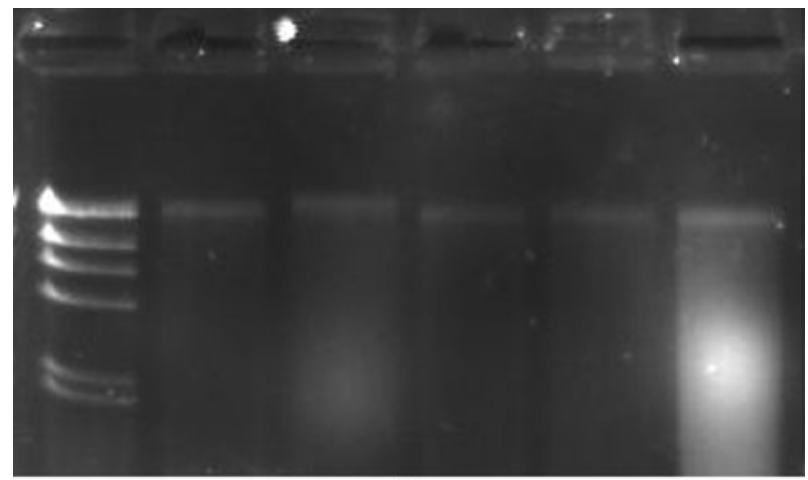

(A)

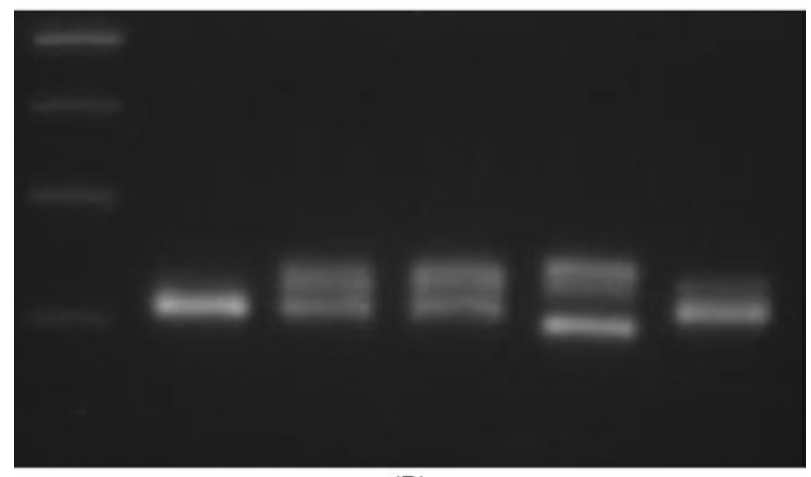

(B)

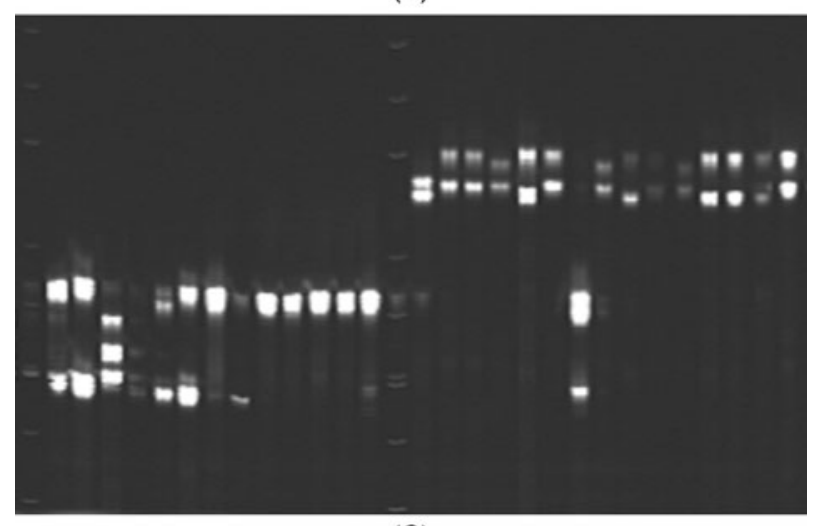

(C)

Figure 1. Representative student-produced agarose gel electrophoresis of DNA extracted from five unknown farm-collected cassava samples (A), the subsequent PCR amplification with SSRmarker "SSR182" (B), and PAGE of 13 unknown cassava samples, each assessed with SSR-markers "SSR4" (left) and "SSR103" (right) (C). In each gel, a molecular weight marker is also shown.

requirement of trained personnel to operate the software and the equipment. Each lab section was brought in front of the LI-COR 4300, and the process of electrophoresis was explained and pertinent information was provided verbally. After completion of the electrophoresis, each group of students was provided the gel image to analyze the allelic diversity for the five cassava samples they ran based on one SSR marker (Figure 1C). Subsequently, all the student groups in a particular lab section evaluated one another's samples. Thus, the students were able to identify and understand the differences between SSR markers, as well as the difference between cassava samples based on each SSR markers.

\section{Starch Quantification and Stomatal and Root Observations}

Each group of students (two students per group) performed its own cassava root sample preparation for the starchquantification portion of the exercise. Each student group was able to complete sample preparation and preparation of a dilution series for analysis using Beer-Lambert's equation to determine the starch concentration present in their cassava samples, using known standards as controls. On completion of their analysis, students were asked to compare their results with other groups in search of differences. To enhance the laboratory experience and maximize available time $(3 \mathrm{~h}$ maximum), each TA received a handout before the laboratory session and a set of slides with specific time-management instructions. For instance, during long incubation steps, each student performed other module-related activities, such as leaf surface area estimates. These measurements were collected and subsequently analyzed in the research lab and correlated with relevant variables (growth conditions, soil type, etc.). Even though no significant trend emerged from the data, it provided an opportunity for students to apply math concepts in the context of the module.

\section{Assessment of Student Learning}

The objective of these laboratory module implementations was to introduce students to research and allow them to meaningfully contribute to an actual research project. We used a culturally relevant problem to engage the largest possible number of students in this activity. In this context, we aimed to teach $800+$ undergraduate students the principles and techniques for proper sample collection, DNA extraction, PCR, SSR molecular marker assessment, gel electrophoresis, and basic light microscopy, as well as quantitative and qualitative starch assessment. Through hands-on practical experience, we also sought to improve students' confidence in learning, understanding, and performing experimental inquiry-based science. Knowledge and confidence tools were used to assess students' learning and confidence building before and after module implementation. The gain-ofknowledge assessment tool was initially used during the pilot implementation in the genetics course. Taught by the same TA, the students in the pilot section (including the new cassava module) showed higher gain of knowledge between the pre- and postmodule assessments compared with the control section (excluding the new cassava module; see Supplemental Material). In both sections, the overall content knowledge in the premodule assessment was $\sim 42 \%$. In the postmodule assessments, the students in the pilot section reported an overall content knowledge increase up to $86 \%$, while the control section students reported only a modest increase up to $54 \%$. In the cell biology pilot implementation, due to a miscommunication with the TA involved, proper assessment could not be completed.

During the subsequent full-implementation semesters, 284 and 264 students in the genetics course, as well as 99 and 120 students in the cell biology course, were exposed to the cassava laboratory modules described here. Previous exposure 
to theoretical aspects of cell and molecular biology offered in introductory biology courses explains the high premodule knowledge. For instance, in the premodule assessment for the genetics course administered during the two semesters of implementation, $50 \%$ and $75 \%$ of the students reported that they understood the definition of molecular biology (GCQ2), while $73 \%$ and $75 \%$ reported having prior knowledge in the uses of gel electrophoresis (GCQ3; Figure 2A). Students enrolled in the cell biology module reported $62.5 \%$ and $60 \%$ knowledge of "cell biology" (CCQ2) and 80\% and 78.8\% of techniques associated with the field (CCQ4), before each semesters' module implementations (Figure 2B). However, there was a slight postmodule increase in GCQ2 to 69\% and $80 \%$, and in GCQ3 to $80 \%$ and $92 \%$, during the two semesters (Figure 2A). Similar results were observed for the cell biology module (Figure 2B; CCQ2 and CCQ4). In general, during the first full implementation of the genetics module, premodule assessment tools reported $>50 \%$ of students chose the correct answer for only one out of seven questions (Figure 2A), while postmodule assessment showed that $>50 \%$ of students in that cohort correctly answered six out of the seven questions. During the second implementation semester, $>50 \%$ of students correctly answered three of seven questions prior to the module, and improved to seven out of seven after module implementation (Figure 2A). Similar results were observed with students enrolled in the cell biology module (Figure 2B).

Overall, there was a significant increase in students' ability to correctly answer postmodule content questions compared with premodule questions. This was particularly true for questions that were more specific to the module (Figure 2A; GCQ5-GCQ7) for students enrolled in the genetics course. In the cell biology module, we did not see a trend of greater improvement in the module-specific questions compared with general questions but observed improvement in both categories of questions during the semesters (Figure $2 \mathrm{~B}$ ). Based on our assessments, the student handout was revised, and a new TA handout and presentation were created.

Normalizing the results of the postmodule assessment for each question, based on the percentage of students who answered correctly in the premodule assessment, shows an overall improvement of $66 \%$ and $55 \%$ in the first and second semesters, respectively, in the genetics course (Figure 2C). There was an improvement in all the questions, with GCQ7 ("What is the use of RNase in nucleotide extractions?") showing the highest increase of $155 \%$ and $177 \%$ during the first and second semesters, respectively. This translates to having $>2.5$ times more students learning and understanding the use of RNase in molecular biology experiments, compared with the beginning of the semester. A high percentage of student improvement was also observed through GCQ5 ("Which of the following techniques is not associated with molecular biology?") and GCQ6 ("What is the enzyme used in the amplification of DNA in PCR technique?"), with the number of students answering correctly almost or actually doubling in both semesters. Students in the cell biology module showed similar improvement, though not as strongly as in the genetics course. In particular, students showed increased learning and understanding in specific module knowledge, for instance "What is the compound used in starch quantification?" (Figure 2D; CCQ5). After normalizing the results based on the premodule assessment, we found students in the cell biology course had an overall improvement of $24 \%$ and $15 \%$ in the two semesters.

One of the disappointments was the student response to question GCQ1 ("Why is cassava an important crop in this world?"; Figure 2A). Cassava being an important crop in Third World countries, and also being part of local cuisine, we expected a higher correct response rate in both pre- and the postmodule assessment tools. Even though there was a twofold and a 1.5-fold increase in the number of genetics students answering correctly in the two semesters (Figure 2C), only $50 \%$ and $57 \%$ of the students answered this question correctly in the postmodule (Figure 2A). In the cell biology course, assessment tools report a similar trend (twofold and 1.75-fold increases, respectively; Figure 2D). Nevertheless, a higher proportion of students (91\% and 63\%) answered correctly in the cell biology postmodule compared with their performance in the genetics course (Figure 2B). A possible explanation could be related to the TAs' discussion and emphasis of the overall importance of cassava. Thus, in the subsequent implementations, more emphasis was given to the overall value of cassava as a source of food and nutrition during the end-of-semester, TA-led discussion. Interestingly, the fact that most students take genetics prior to cell biology may explain the higher correct response rate in the latter course.

\section{Assessment of Student Confidence}

To assess whether our module had an impact on student confidence, we developed a postmodule survey using a 5-point Likert scale (Figure 3). When students were asked whether they were confident "designing experiments to test a hypothesis" in both a cell (CPQ2) and genetics (GPQ3) laboratory, our assessment tools report that roughly $50 \%$ of the students report themselves as "very confident" or "confident." With the exception of that question, $\sim 60 \%$ or more students in the genetics course perceived themselves as "very confident" or "confident" in all other catogories (Figure 3A). In the cell biology module, the majority of students $(60 \%$ or more) reported high confidence in all questions, except those related to designing experiments and scheduling activities related to those experiments. In those questions, 34.4\% (CPQ2) and $41.3 \%$ (CPQ3) self-reported as "very confident" or "confident," respectively.

Given the large number of students enrolled in both courses, and considering their diverse backgounds, we believe that the self-reported confidence gain met our expectations. Of significance is that students in both cell and genetics laboratories report an increased confidence in their abilities to "properly and safely use lab equipment" (>85\% and $>73 \%$, in GPQ5 and CPQ4, respectively; Figure 3) and "observe and collect data" (>90\% and $>72 \%$, in GPQ6 and CPQ5, respectively; Figure 3) through the implemented modules. From a perspective of cell and molecular biology training, $68-72 \%$ of students enrolled in the genetics teaching laboratory agreed they are "very confident" or "confident" in "learning theoretical aspects of modern molecular biology techniques" (GPQ9), while $65-69 \%$ students in cell biology reported similar results in terms of cell biology techniques (CPQ7). When students in the genetics laboratory were asked whether they were "very confident" or "confident" in "learning the practical uses of 
(A)

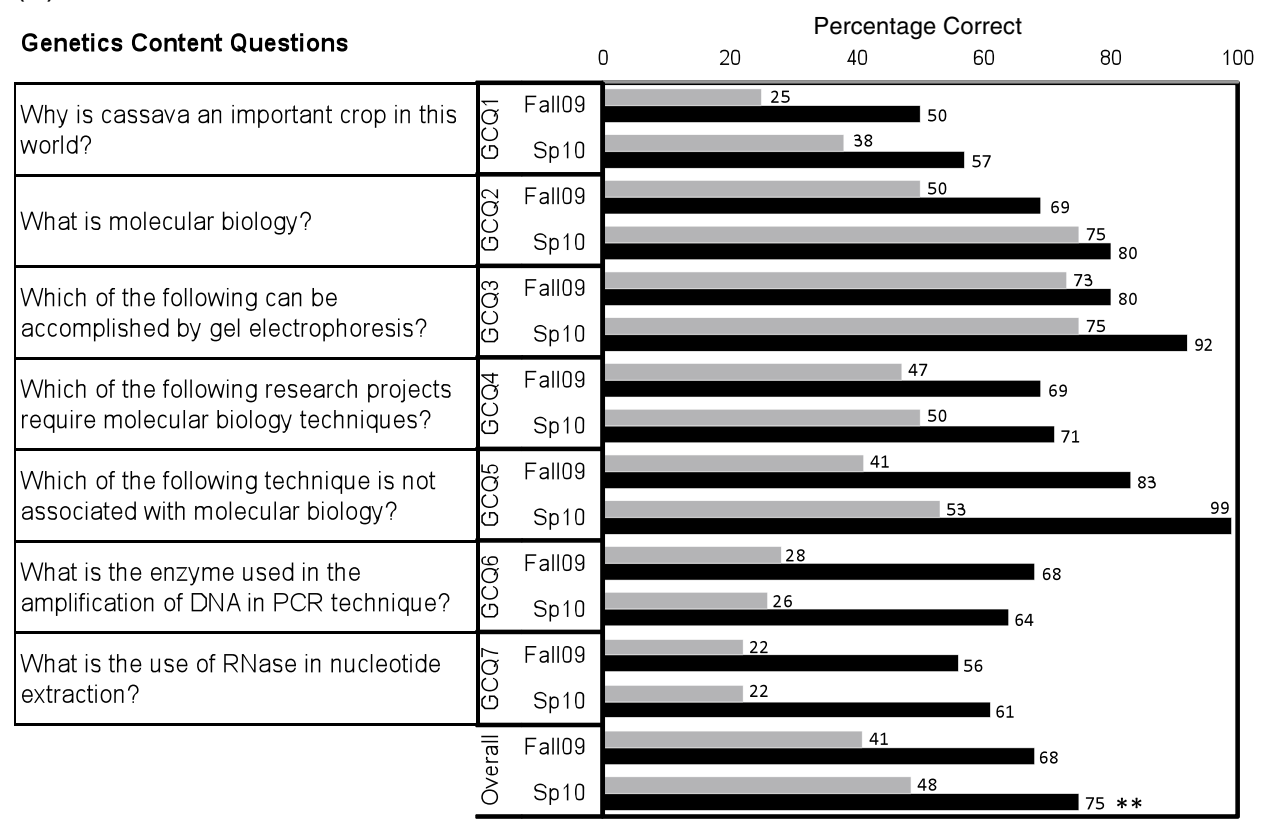

- Pre-Module - Post-Module

Fall09 semester $n=284$; Sp10 semester $n=264$

(B)

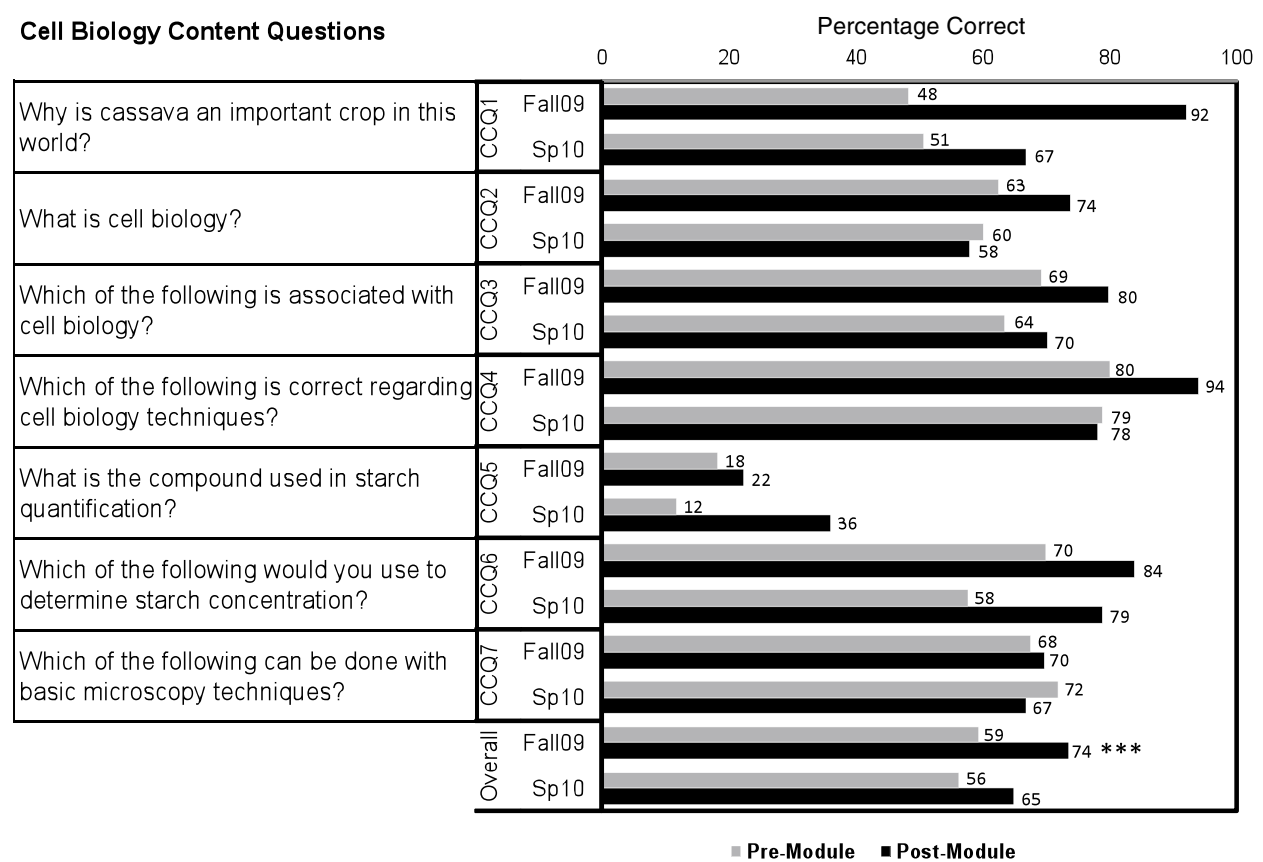

\section{Fall09 semester $n=99$; Sp10 semester $n=120$}

Figure 2. Gains in content knowledge. Assessment of knowledge gained by students through pre- and postmodule assessments consisting of seven questions. Percentage correct per question in the premodule (gray bars) and postmodule (black bars) assessments during Fall 2009 and Spring 2010 semester in the genetics (A) and cell biology (B) courses. The last horizontal bars show the overall percentages. Percentage increase of the number of students obtaining the correct answer per question as a result of the implementation of the lab module (postmodule data normalized for the premodule data) in the genetics (C) and cell biology (D) courses. GCQ and CCQ refer to "genetics content question" and "cell biology content question," respectively. The overall scores in the posttests were higher $\left({ }^{*} p<0.01 ; * *<0.05\right.$; $\left.{ }^{* * *} p<0.1\right)$ as determined using an unpaired $t$ test. (Continued) 
(C)

Genetics Content Questions

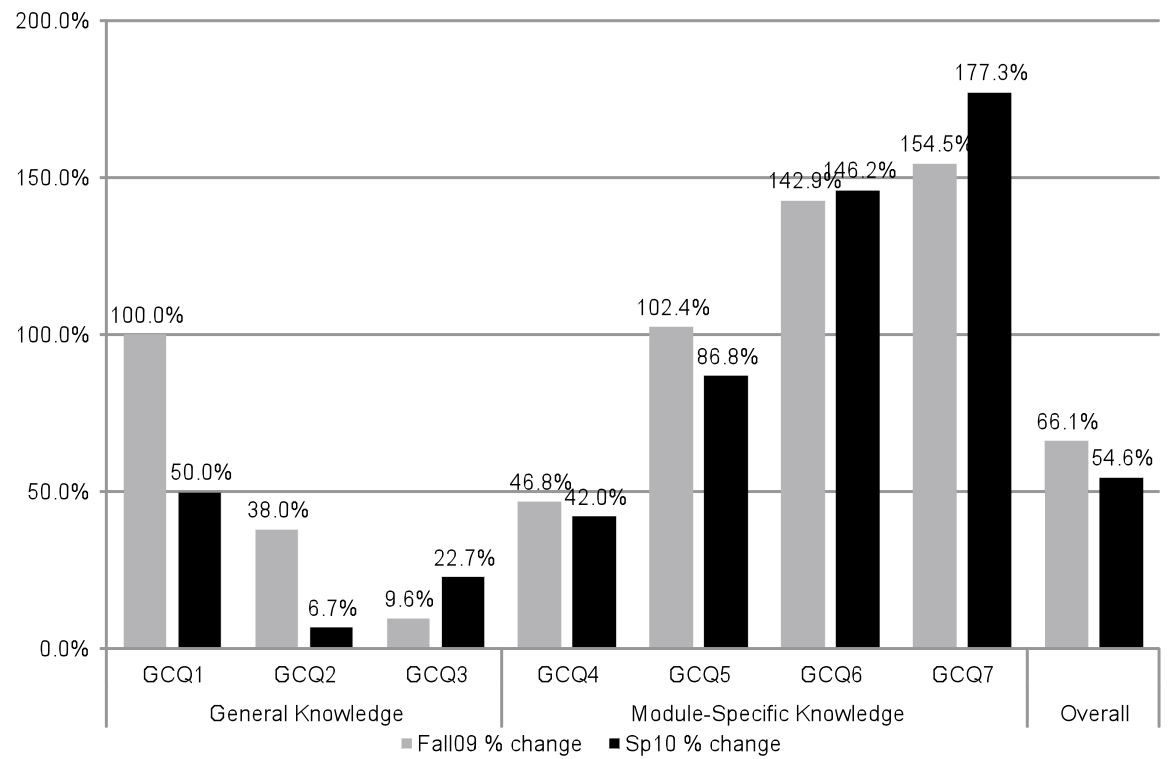

(D) Cell Biology Content Questions

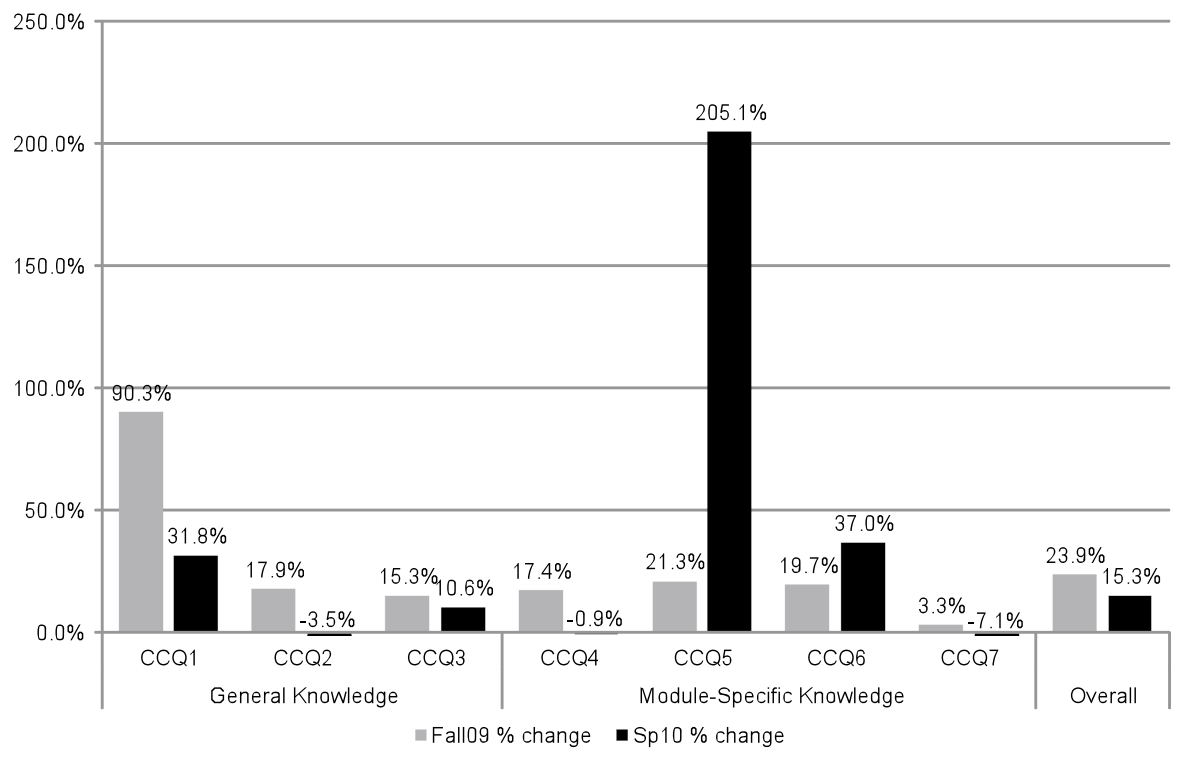

Figure 2. Continued.

molecular biology techniques in research projects" (GPQ10) and "performing well in a scientific research project using PCR" (GPQ13) as a result of their participation in the lab module, $72-74 \%$ and $65-66 \%$, respectively, agreed (Figure 3A). Students in cell biology reported similar perception gains (Figure 3B). As a result of using cassava as the platform in this lab module, $61 \%$ and $63 \%$ of the students during the two semesters agreed that they are "very confident" or "confident" in "comprehending topics in agricultural biotechnol- ogy" (GPQ11), which is an emerging field of immense importance (Figure 3A).

\section{Assessment of Cassava Diversity in Puerto Rico}

Through this lab module, we were able to achieve our research objective by thoroughly assessing the genetic diversity of cassava in Puerto Rico. This is the first comprehensive evaluation of cassava in the Caribbean region. The undergraduate 
(A) Genetics Perception Questions

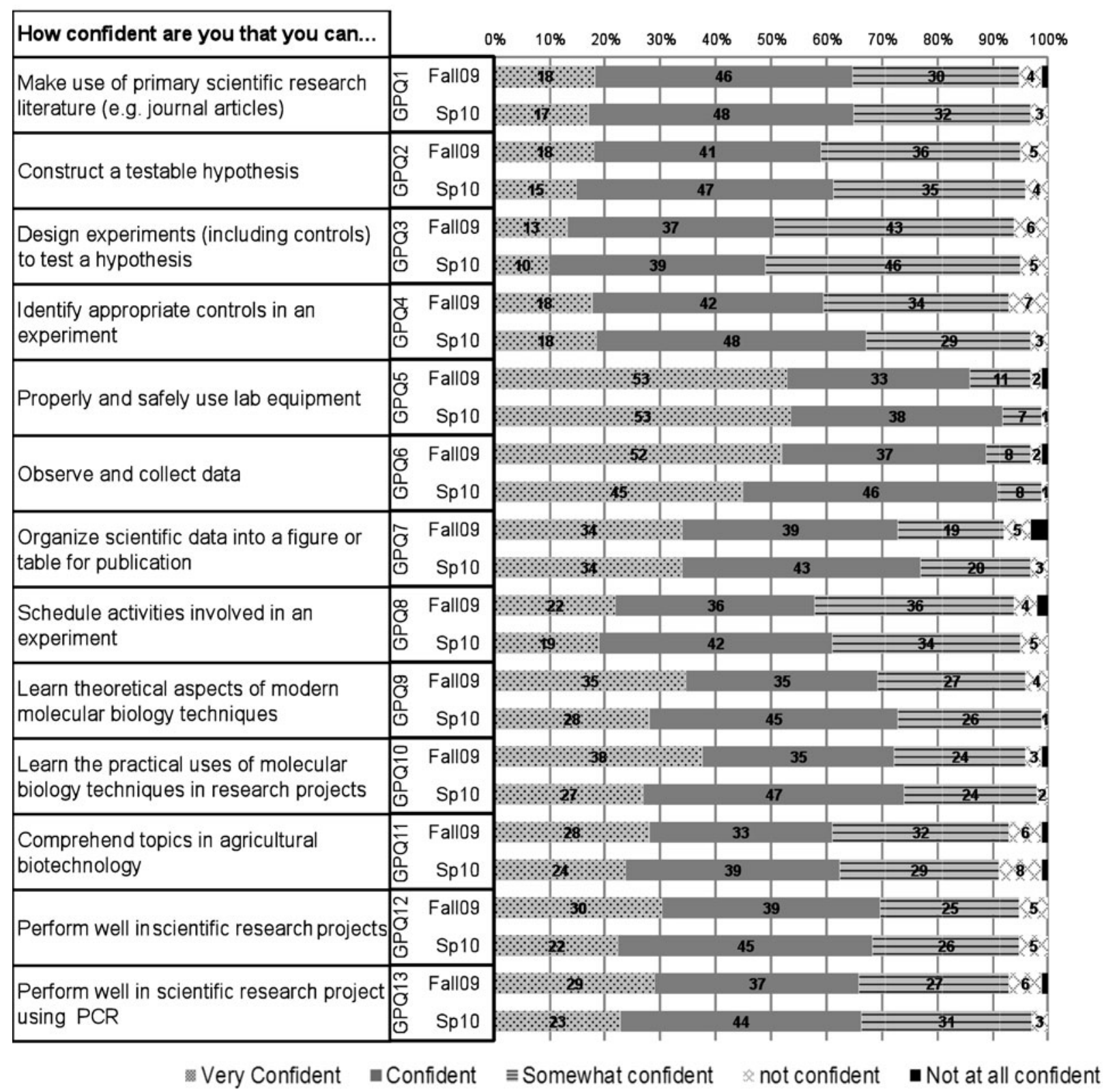

Figure 3. Gains in confidence. Assessment of self-confidence postmodule measured using a 5-point Likert scale $(5=$ very confident, $4=$ confident, 3 = somewhat confident, $2=$ not confident, and $1=$ not at all confident) in genetics (A) and cell biology (B). GPQ and CPQ refer to "genetics perception question" and "cell biology perception question," respectively. (Continued)

students in the genetics course used five SSR markers with the highest polymorphism information content value in their analysis. The same samples were subjected to a more vigorous assessment of diversity using 33 SSR markers as part of a thesis project of a graduate student in the PI's research laboratory (Montero-Rojas et al., 2011). These samples of unknown genetic background were also compared with the Puerto Rican cassava germplasm, which consists of 23 different cultivars and accessions (Montero-Rojas et al., 2011).
Beyond achieving both our research and education objectives, our assessments demonstrate that our module implementation had a positive impact on students. Our approach differs significantly from the traditional "recipe-based" teaching laboratory, in which students can easily anticipate expected results, and moves to engage them in a researchoriented experience. It allows the student to be actively engaged from the very beginning (sample collection) to the end, in a laboratory sequence that spans two courses over two 


\section{(B) Cell Biology Perception Questions}

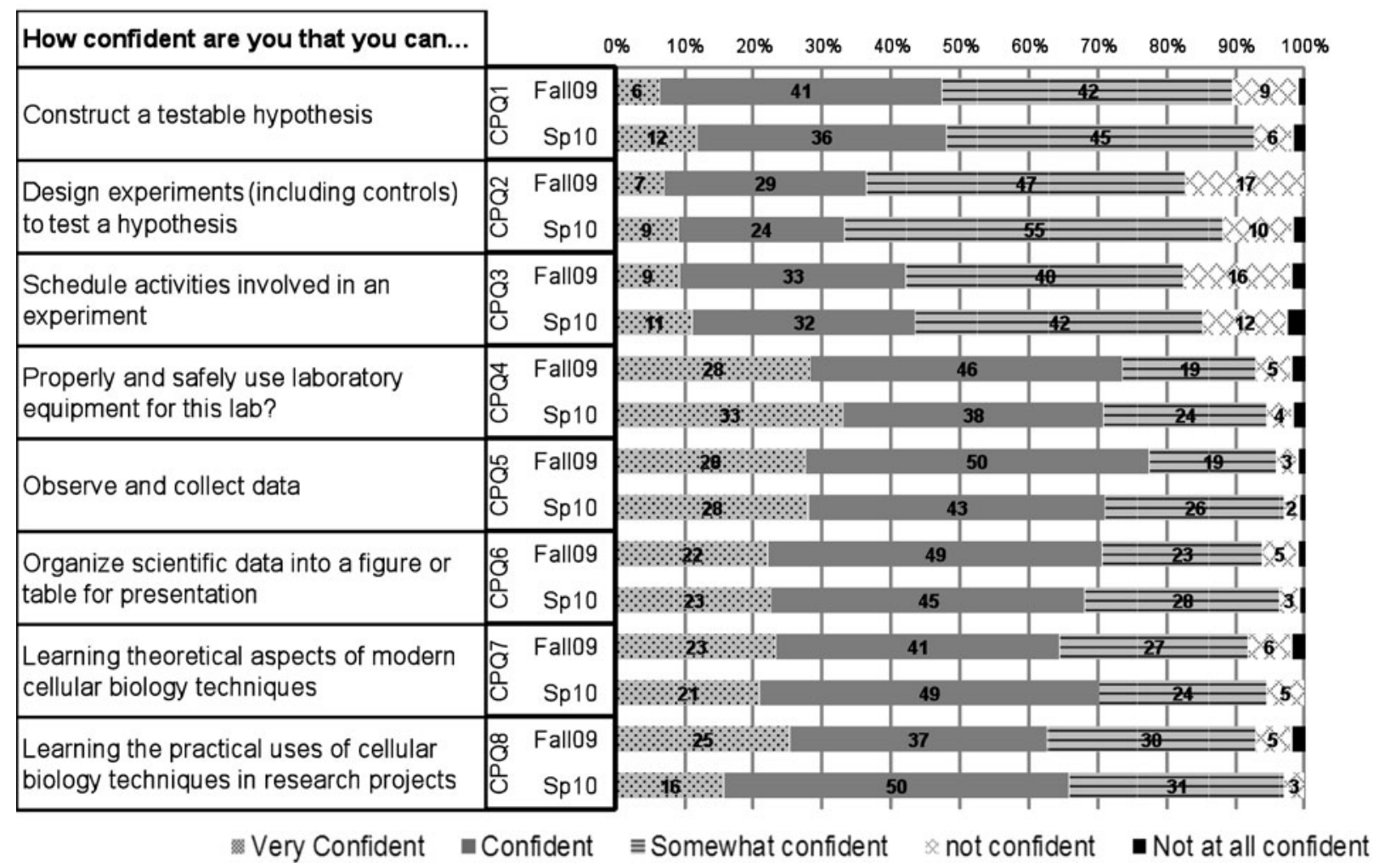

Figure 3. Continued.

semesters and uses a variety of scientific tools to analyze various aspects of a research question. Thus, this learning experience closely resembles the multidisciplinary nature of modern research. The selection of cassava, a common food source in Puerto Rico, as a model to develop and implement these modules further enhances student understanding of the experience, as it relates to a part of their daily activities. When thoughtfully conceived, local adaptations provide models for increased relevance to students, regardless of age and background (Fields, 2010). This is of particular relevance amid calls for increasing diversity in science, technology, engineering, and mathematics (STEM) careers (National Academy of Sciences, 2010; National Institute of General Medical Sciences, 2011), in particular for Latinos (Malcom et al., 2010), and its benefits to academia (Smith, 1997). We believe our modules represent a successful strategy for increasing participation of underrepresented minority students in STEM careers.

\section{ACKNOWLEDGMENTS}

We thank Lorraine Rodríguez-Bonilla and Jean Seda-López for help in developing the laboratory modules. Special thanks also to Terry Woodin (National Science Foundation, Arlington, VA) for critical review of this manuscript. We also thank the TAs in the genetics and cell biology courses during Spring 2009, Fall 2009, and Spring 2010 semesters for their efforts and willingness to participate in the implementation of these modules. This work was funded by a grant from the Course Curriculum and Laboratory Improvement program of the National Science Foundation (DUE-736727).

\section{REFERENCES}

Cabral GB, Carvalho LJCB (2001). Analysis of proteins associated with storage root formation in cassava using two-dimensional gel electrophoresis. R Bras Fisiol Veg 13, 41-48.

Cox T, Murphy J, Rodgers D (1986). Changes in genetic diversity in the red winter wheat regions of the United States. Proc Natl Acad Sci USA $83,5583-5586$.

Dellaporta S, Wood J, Hicks J (1983). A plant DNA minipreparation: version II. Plant Mol Biol Reporter 1, 19-21.

Fields H (2010). Making research personal. Sci Educ HHMI Bull 23, 38-39.

Fregene M, et al. (2003). Simple sequence repeat marker diversity in cassava landraces: genetic diversity and differentiation in an asexually propagated crop. Theor Appl Genet 107, 1083-1093.

Goenaga R, Rivera-Amador E, Chardon U (2002). Yield performance of introduced cassava clones in an ultisol in Puerto Rico. J Agric Univ Puerto Rico 86, 27-33.

Hathaway RS, Nagda BA, Gregerman SR (2002). The relationship of undergraduate research participation to graduate and professional education pursuit: an empirical study. J Coll Stud Dev 43, 614663.

Hovenkamp-Hermelink JHM, De Vries JN, Adamse P, Jacobsen E, Witholt B, Feenstra WJ (1988). Rapid estimation of the amylose/amylopectin ratio in small amounts of tuber and leaf tissue of the potato. Potato Res 31, 241-246.

Hunter A-B, Laursen SL, Seymour E (2007). Becoming a scientist: the role of undergraduate research in students' cognitive, personal, and professional development. Sci Educ 91, 36-74. 
Kizito E, Bua A, Fregene M, Egwang T, Gullberg U, Westerberg A (2005). The effect of cassava mosaic disease on the genetic diversity of cassava in Uganda. Euphytica 146, 45-54.

Lord T, Chad S, Zimmerman R (2007). Putting inquiry teaching to the test: enhancing learning in college botany. J Coll Sci Teach 36, 6265.

Malcom LE, Dowd AC, Yu T (2010). Tapping HSI-STEM Funds to Improve Latina and Latino Access to the STEM Professions. Los Angeles, CA: University of Southern California.

Mohammadi S, Prasanna B (2003). Review \& interpretation. Analysis of genetic diversity in crop plants-salient statistical tools and considerations. Crop Sci 43, 1235-1248.

Montero-Rojas M, Correa A, Siritunga D (2011). Molecular differentiation and diversity of cassava (Manihot esculenta) taken from 162 locations across Puerto Rico and assessed with microsatellite markers. AoB Plants. doi: 10.1093/aobpla/plr010.

Morgante M, Olivieri A (1993). PCR-amplified microsatellites as markers in plant genetics. Plant J 3, 175-182.

National Academy of Sciences. (2010). Expanding Underrepresented Minority Participation: America's Science and Technology Talent at the Crossroads, Washington, DC: National Academies Press.

National Institute of General Medical Sciences (2011). Investing in the Future: Strategic Plan for Biomedical and Behavioral Research
Training. http://publications.nigms.nih.gov/trainingstrategicplan (accessed 6 July 2011) .

National Research Council (NRC) (2000). Inquiry and the National Science Education Standards: A Guide for Teaching and Learning, Washington, DC: National Academies Press.

NRC (2003). BIO 2010: Transforming Undergraduate Education for Future Research Biologists. Committee on Undergraduate Biology Education to Prepare Research Scientists for the 21st Century, Washington, DC: National Academies Press.

Prince M, Felder RM (2007). The many faces of inductive teaching and learning. J Coll Sci Teach 36, 14-20.

Russell SH, Hancock MP, McCullough J (2007). The pipeline: benefits of undergraduate research experiences. Science 316, 548-549.

Seymour EL, Hunter A-B, Laursen S, DeAntoni T (2004). Establishing the benefits of research experiences for undergraduates: first findings from a three-year study. Sci Educ 88, 493-594.

Shaffer CD et al. (2010). The genomics education partnership: successful integration of research into laboratory classes at a diverse group of undergraduate institutions. CBE Life Sci Educ 9, 55-69.

Smith J (1984). Genetic variability within U.S. hybrid maize: multivariate analysis of isozyme data. Crop Sci 24, 1041-1046.

Smith D (1997). Diversity Works: The Emerging Picture of How Students Benefit, Washington, DC: Association of American Colleges and Universities. 